\title{
A primitive approach to Ou MC decrescendo phenomenon with a hands-on therapy-The relation between human bilateral symmetry and disease
}

\author{
Ming Cheh $\mathrm{Ou}^{1,2^{\star}}$, Dennis $\mathrm{Ou}^{3}$, Chung Chu Pang ${ }^{4}$ \\ ${ }^{1}$ Department of Gynecology and Obstetrics, Taipei City Hospital, Taipei City, Taiwan; *Corresponding Author: mcou@ym.edu.tw \\ ${ }^{2}$ Department of Gynecology and Obstetrics, Taipei Medical University, Taipei City, Taiwan \\ ${ }^{3}$ Department of Mechanical Engineering and Biomedical Engineering, Carnegie Mellon University, Pittsburgh, USA \\ ${ }^{4}$ Department of Gynecology and Obstetrics, Su Women Hospital, Taipei City, Taiwan
}

Received 4 January 2014; revised 4 February 2014; accepted 11 February 2014

Copyright (C) 2014 Ming Cheh Ou et al. This is an open access article distributed under the Creative Commons Attribution License, which permits unrestricted use, distribution, and reproduction in any medium, provided the original work is properly cited. In accordance of the Creative Commons Attribution License all Copyrights (c) 2014 are reserved for SCIRP and the owner of the intellectual property Ming Cheh Ou et al. All Copyright (C) 2014 are guarded by law and by SCIRP as a guardian.

\section{ABSTRACT}

The Ou MC decrescendo phenomenon (OuDP) involves the placing of the contralateral hand of the examiner on the acute abdomen of female patients (Ou MC manipulation), which results in an alleviation of pain [1]. Two front-end observations showed that placement of the contralateral hand on the acute abdomen of women alleviated pain (78 of 81 women or $96.3 \%$ ), while placement of the ipsilateral hand did not ( 0 of 39 women or $0 \%$ ). This method named as Ou MC handing remedy (HR) was used to observe the immediate and cumulative effects of OuDP on 38 cases, of which 27 were self-administered and 11 were administered by the therapist. The mean age of the patients was 55.8 years (standard deviation, 22.9 years). Five minutes after initial self-administered HR, there was pain alleviation in 14 cases and symptoms or signs beyond pain improved for another 6 cases while 7 cases unevaluated. Final results showed 9 cured, 5 with partial remission and the remaining 13 with complete remission. Five minutes after initial therapist-administered HR, pain alleviation was found with 10 cases while 1 case unevaluated. The final results showed 7 cases cured, 2 with partial remission, and 2 with complete remission. The resolution of non-infectious conditions (23) 38) with OuDP is consistent with the restoration of normal tissue function, which seems to contribute to pain alleviation and defense against infections and tumors. Interestingly, the OuDP is capable of being invoked by either the patient or the therapist. These findings warrant further investigation.

\section{KEYWORDS}

Ou MC Decrescendo Phenomenon; Pain; Inflammation; Oncological Change; Hands-On Treatment; Restoration of Normal Tissue Function

\section{INTRODUCTION}

The mechanisms involved in mutual interactions between bilateral parts of topographically symmetrical living beings remains largely unknown, but there are indications that it may occur via neurological transmission [2]. Studies have shown that such interactions may induce and reinforce inflammatory reactions and pain sensations on the contralateral side of the body. Examples of such phenomena are contralateral arthritis induced by unilateral arthritis in rats and, in humans, symmetrically developed arthritis, pulmonary fibrosis, glomerulonephritis and sympathetic ophthalmia [2]. The Ou MC manipulation method results in the Ou MC decrescendo phenomenon (OuDP), which involves the alleviation of pain by the placement of the contralateral hand of the examiner on the acute abdomen of a female patient [1]. Two front-end studies were performed from 2006 to 2011 (Table 1). The first study showed that a deeply placed contralateral hand was able to alleviate the acute abdominal pain of 42 women. The second study compared the effect of contralateral to ipsilateral hands when used to alleviate the acute abdomen pain of 39 women. 
Table 1. Front-end observations of the immediate effects of the Ou MC decrescendo phenomenon when treating the acute abdomen pain of 81 women.

\begin{tabular}{|c|c|c|c|c|c|c|}
\hline \multirow{2}{*}{ Study } & \multirow{2}{*}{ Author (years) } & \multirow{2}{*}{ Pain } & \multirow{2}{*}{$\begin{array}{c}\text { Number of } \\
\text { patients }\end{array}$} & \multirow{2}{*}{ Treatment } & \multicolumn{2}{|c|}{ Alleviation of pain } \\
\hline & & & & & Contralateral hand & Ipsilateral hand \\
\hline 1 & $\begin{array}{c}\text { Ou et al. } \\
(2006-2009)\end{array}$ & $\begin{array}{l}\text { Adjourning region to } \\
\text { the diseased area }\end{array}$ & 42 & Ou MC manipulation ${ }^{\mathrm{a}}$ & $100 \%(42 / 42)$ & Not performed \\
\hline 2 & $\begin{array}{c}\text { Ou et al. } \\
(2010-2011)\end{array}$ & Diseased area & $39^{\mathrm{b}}$ & $\begin{array}{l}\text { 5-10 seconds } \\
\text { (Figure } 1, \mathrm{C}-1 \text { or } 2 \text { ) }\end{array}$ & $91.9 \%(36 / 39)^{\mathrm{c,d}}$ & $0 \%(0 / 39)^{\mathrm{d}}$ \\
\hline
\end{tabular}

${ }^{\mathrm{a}}$ For example, put right hand of the examiner to the left abdominal area of the patient and deeply separate pelvic organ for more than 15 seconds [1]; ${ }^{b}$ Mean age of 43 (standard deviation, 14.3); 6 with appendicitis, 29 with PID, 2 with dysmenorrhea, 1 with cystitis, 1 with corpus luteum rupture with criteria in Study 1 ; ${ }^{\circ} 3$ ( 1 with appendicitis, 2 with PID) did not show alleviation of pain; ${ }^{\mathrm{d}}$ Difference between contralteral and ipsilateral hand for alleviation of pain, $p<0.001$, Paired t test.

In this case, usage of the contralateral hand alleviated the pain of $92.3 \%$ of women (36/39), while the ipsilateral hand did not $(0 / 39)$ ( $p<0.001$, Paired t test). Hands-on therapies usually show measurable immediate effects when relieving clinical symptoms of patients, but do not eliminate the underlying diseases $[3,4]$. Thus, the OuDP requires further observation to justify its clinical significance.

As a hand manipulation, Ou MC handing remedy (HR) [5] was performed by a therapist or self-administered by the patient to investigate not only the immediate but also cumulative effect of OuDP in a series of patients with conditions that might not respond, or were not amenable, to more conventional treatments. This study is a primitive observation of the clinical effects of OuDP. Thus, the clinical approach to each case was to collect detailed records that can serve as reference and further approach into the underlying mechanism.

Emotional improvements have also been associated with objective improvements in clinical variables, such as decreased viral load and increased CD4+ lymphocyte counts in patients with HIV infection [6]. Similarly, emotional improvements as a result of mind-related stress reduction have been associated with a shift away from a proinflammatory response toward an anti-inflammatory response, as well as reductions in tumor size $[7,8]$. Such emotional factors are likely plays a role in the effectiveness of hand-based remedies [9]. Based on the above, the generalized anxiety disorder-7 item scale (GAD-7) was used to assess the potential impact of anxiety on treatment outcome [10].

\section{METHODS}

\subsection{Subjects}

Thirty eight patients were recruited from June 2011 to November 2013. Of these, 27 were trained to administer HR by themselves (Tables 2, 3) and the other 11 received HR by the therapist (Table 4). Complementary therapy is exempt from informed consent by investigational review boards by law in Taiwan [11]. Nevertheless, all patients were provided informed consent for partici- pation in this study and categorized into three groups: Group 1 comprised eleven patients with symptoms or signs related to infection treated with self-adminitered HR (Table 2), Group 2 comprised sixteen patients with symptoms or signs not related to infection treated with self-administered HR (Table 3) and Group 3 for the eleven patients treated by the therapist (Table 4). No metabolic or immunological diseases were identified in these patients. All patients refrained from medication during the study period, except for the use of antibiotics by three patients (treatment of cellulitis of the right leg in case 5, a laceration wound of the upper eyelid in case 22 and right tuboovarian abscess in case 30), Glivec for case 23, L-dopa for case 26 and oral ergonovine maleate and tranexamic acid for the initial 5 days of the 3 weeks HR treatment for case 27 . The mean age of the patients (17 men, 21 women) was 55.8 years (standard deviation, 22.9 years).

\subsubsection{Group 1. Patients with Symptoms or Signs Related to Infection}

Table 2 provides an overview of the conditions treated in Group 1. Patient 1 had recurrent oropharyngeal infection that became exacerbated in the absence of antibiotic treatment. Patient 2 had a tender suppurative mucosal swelling of the sublingual and gingival areas on the right side of the mouth. Patient 3 had a brownish granuloma on the left index finger. The lesion gradually enlarged over a 2-week period after the patient discontinued antibiotic treatment, suggesting an infectious origin. No cultures or other diagnostic tests were performed for confirmation. Patient 4 had a reddish pyogenic granuloma on the sternum. Patient 5 had intractable subcutaneous edematous swelling of the right leg caused by cellulitis. It had been treated with intravenous empirical antibiotics and far infrared ray (FIR) therapy for 2 weeks; cultures carried out on blood and cellulitis showing negative. Patients 6 and 7 had a roughly 1-week history of yellowishwhite mucous rhinorrhea without fever. Patients 8 and 9 had influenza diagnosed clinically, although a test with low sensitivity (EZ Flu A + B immunoassay test, Beck Dickson, Sparks, MD, USA) yielded negative results for 
Table 2. Effects of Ou MC decrescendo phenomenon using the self-administered Ou MC handing remedy (HR) on the symptoms and signs of disease related to infection (Group 1).

\begin{tabular}{|c|c|c|c|c|c|c|c|}
\hline Case & Clinical presentations & Age/Sex & Treatment & S/S evaluated & Effect $^{\mathrm{a}}$ & Duration & Result \\
\hline 1 & $\begin{array}{c}\text { Pain with recurrent } \\
\text { oropharyngeal infection }\end{array}$ & $51 / \mathrm{M}$ & $\begin{array}{l}30 \mathrm{sec}-5 \mathrm{~min} / 2-3 \\
\text { times/day }\end{array}$ & pain & Alleviated & 1 week & Cure \\
\hline 2 & $\begin{array}{l}\text { Pain with right sublingual } \\
\text { and gingival infection }\end{array}$ & $58 / \mathrm{M}$ & $1 \mathrm{~min} / 2$ times/day & pain & Alleviated & 4 days & Cure $^{\mathrm{b}}$ \\
\hline 3 & $\begin{array}{l}\text { Infectious granuloma of } \\
\text { left index finger }\end{array}$ & $44 / \mathrm{F}$ & $5 \mathrm{~min} / 2$ times/day & size & ND & 1 week & Cure \\
\hline 4 & $\begin{array}{l}\text { Infectious granuloma on } \\
\text { sternal area of chest }\end{array}$ & $64 / \mathrm{M}$ & $\begin{array}{l}1 \text { min on each side of the } \\
\text { granuloma/2 times/day }\end{array}$ & size & ND & 4 days & Cure \\
\hline 5 & $\begin{array}{l}\text { Edematous swelling of } \\
\text { right leg with cellulitis }\end{array}$ & $87 / \mathrm{F}$ & $\begin{array}{l}30 \mathrm{~min} \text { on } 1 \text { st day, then } 20 \\
\mathrm{~min} / 2-3 \text { times/day }\end{array}$ & size & Alleviated & 3 days & Cure \\
\hline 6 & Rhinorrhea & $6 / \mathrm{F}$ & $\begin{array}{l}5 \text { min on each paranasal } \\
\text { area/2 times/day }\end{array}$ & amount & Decreased & 2 days & $\mathrm{PR}^{\mathrm{c}}$ \\
\hline 7 & Rhinorrhea & $60 / \mathrm{M}$ & $\begin{array}{l}1 \text { min on each paranasal } \\
\text { area/2 times/day }\end{array}$ & amount & Decreased & 2 days & $\mathrm{PR}^{\mathrm{c}}$ \\
\hline 8 & Headache & $58 / \mathrm{F}$ & $\begin{array}{l}5 \text { min for each temporal } \\
\text { area, then } 2 \text { - } 3 \text { min during } \\
\text { headache episodes }\end{array}$ & pain & Alleviated & 3 days & $\mathrm{CR}^{\mathrm{c}}$ \\
\hline 9 & Headache & $22 / \mathrm{M}$ & $\begin{array}{l}5 \text { min for each temporal } \\
\text { area, then } 2 \text { - } 3 \text { min during } \\
\text { headache episodes }\end{array}$ & pain & Alleviated & 4 days & $\mathrm{CR}^{\mathrm{c}}$ \\
\hline 10 & Warts & $55 / \mathrm{M}$ & 20 - 30 sec/1 - 2 times/day & size & ND & 2 months & Cure \\
\hline 11 & Wart & 59/M & $20-30 \mathrm{sec} / 3$ times/day & size & ND & 1 month & Cure \\
\hline
\end{tabular}

S/S: Symptoms or Signs; min: minute(s); ND: no data (unevaluated); PR: partial remission; CR: complete remission. ${ }^{\mathrm{a}}$ Evaluated in 5 minutes after initial session of treating disease; ${ }^{b}$ Cured after changing extraoral to intraoral HR; ${ }^{c}$ Recurrences or aggravations successfully treated with HR.

Table 3. Effects of Ou MC decrescendo phenomenon using the self-administered Ou MC handing remedy (HR) on the symptoms and signs of disease unrelated to infection (Group 2).

\begin{tabular}{|c|c|c|c|c|c|c|c|}
\hline Case & Clinical presentations & Age/Sex & Treatment & S/S evaluated & Effect $^{\mathrm{a}}$ & Duration & Result \\
\hline 12 & Left frozen shoulder & $52 / \mathrm{M}$ & $2 \mathrm{~min} / 2$ times/day & pain & Alleviated & 1 week & $\mathrm{CR}^{\mathrm{b}}$ \\
\hline 13 & Lumbosacral joint pain & $59 / \mathrm{M}$ & 30 sec-1 min/1 - 2 times/day & pain & Alleviated & 1 week & $\mathrm{CR}^{\mathrm{b}}$ \\
\hline 14 & Lumbosacral joint pain & $78 / \mathrm{F}$ & $5 \mathrm{~min} / 2$ times/day & pain & Alleviated & 1 week & $\mathrm{CR}^{\mathrm{b}}$ \\
\hline 15 & Coccygodynia & $42 / F$ & $20 \mathrm{~min} / 3$ times for day 1 and 3 & pain & Alleviated & 3 days & $\mathrm{CR}^{\mathrm{b}}$ \\
\hline 16 & Right hip joint pain & $48 / \mathrm{F}$ & 5 min/1 - 2 times/day & pain & Alleviated & 1 week & $\mathrm{CR}^{\mathrm{b}}$ \\
\hline 17 & Right knee joint pain & $57 / \mathrm{M}$ & 30 sec-1 min/1 - 2 times/day & pain & Alleviated & 1 week & $\mathrm{CR}^{\mathrm{b}}$ \\
\hline 18 & Bilateral hip joint pain & $91 / \mathrm{M}$ & $10 \mathrm{~min} / 2$ times/day & pain & Alleviated & 4 days & CR \\
\hline 19 & Bilateral knee joints pain & $76 / \mathrm{F}$ & 30 sec-1 min/1 - 2 times/day & pain & Alleviated & 1 week & CR \\
\hline 20 & Bilateral knee joints pain & $89 / \mathrm{F}$ & $1 \mathrm{~min} / 3$ times/day & pain & Alleviated & 1 week & CR \\
\hline 21 & $\begin{array}{l}\text { Right knee, and lumbosacral } \\
\text { joint pain }\end{array}$ & $55 / \mathrm{F}$ & 1 - 2 min/2 times/day & pain & Alleviated & 2 days & CR \\
\hline 22 & $\begin{array}{l}\text { Periorbital edematous } \\
\text { swelling of right eye }\end{array}$ & $89 / \mathrm{F}$ & 5 min/1 time/day & size & Alleviated & 3 days & Cure \\
\hline 23 & $\begin{array}{l}\text { Chronic myelogenous leukemia } \\
\text { with perineal cutaneous lesion }\end{array}$ & $39 / F$ & $2 \mathrm{~min} / 2$ times/day & size & ND & 2 week & Cure \\
\hline 24 & Supine cough & $46 / \mathrm{M}$ & On supine before sleep & frequency & Alleviated & 3 months & $\mathrm{PR}^{\mathrm{b}}$ \\
\hline 25 & $\begin{array}{l}\text { Defecation difficulty with small } \\
\text { stool caliber }\end{array}$ & $56 / \mathrm{M}$ & $\begin{array}{c}1 \text { min before sleep and in } \\
\text { defecation }\end{array}$ & function/size & ND & 3 week & $\mathrm{CR}^{\mathrm{b}}$ \\
\hline 26 & Parkinsonism & 87/M & $\begin{array}{l}\text { On bilateral temporal area before } \\
\text { and in sleep or nap }\end{array}$ & function & ND & 2 months & $\mathrm{PR}^{\mathrm{c}}$ \\
\hline 27 & Massive uterine bleeding & $60 / \mathrm{F}$ & 2 - 3 min/4 times/day & frequency/amount & creased/Decreased & 3 weeks & PR \\
\hline
\end{tabular}

S/S: Symptoms or Signs; min: minute(s); Supine cough: persistent cough while lying supine; ND: no data (unevaluated); PR: partial remission; CR: complete remission. ${ }^{\mathrm{a}}$ Evaluated in 5 minutes after initial session of treating disease; ${ }^{\mathrm{b}}$ Recurrences or aggravations successfully treated with HR; ${ }^{\mathrm{C}}$ No aggravation demonstrated in the period of treatment. 
Table 4. Effects of Ou MC decrescendo phenomenon by therapist-administered Ou MC handing remedy (HR) on symptoms and signs of disease related to infection (Group 3).

\begin{tabular}{|c|c|c|c|c|c|c|c|}
\hline Case & Clinical presentations & Age/Sex & Treatment & S/S evaluated & Effect $^{\mathrm{a}}$ & Duration & Result \\
\hline \multicolumn{8}{|c|}{ Diseases related to infection } \\
\hline 28 & $\begin{array}{l}\text { Abdominal pain after biliary } \\
\text { tract infection }\end{array}$ & $92 / \mathrm{F}$ & $2 \mathrm{~min} / 2$ times/day & pain & Alleviated & 1 week & $\mathrm{PR}^{\mathrm{b}}$ \\
\hline 29 & Dysuria and pyuria & $77 / \mathrm{F}$ & $2 \mathrm{~min} /$ week & $\begin{array}{l}\text { pain/urinary leukocyte } \\
\text { count }\end{array}$ & $\mathrm{ND} / \mathrm{ND}$ & 3 week & CR \\
\hline 30 & $\begin{array}{l}\text { Right intractable tuboovarian } \\
\text { abscess with pain }\end{array}$ & $18 / \mathrm{F}$ & $\begin{array}{c}2 \mathrm{~min} / 2 \text { times/day for } 3 \text { days changed } \\
\text { to } 5 \mathrm{~min} / 3 \text { times/day for } 1 \text { week }\end{array}$ & pain/size & Alleviated/ND & 10 days & Cure \\
\hline 31 & $\begin{array}{l}\text { Left periocular swelling with } \\
\text { pain }\end{array}$ & $22 / \mathrm{F}$ & $\begin{array}{c}1 \mathrm{~min} / 1 \text { - } 2 \text { times/day for } 3 \text { days } \\
\text { changed to self-administered HR } 5 \\
\text { min/3 times/day for } 1 \text { week }^{\mathrm{b}}\end{array}$ & pain/size & Alleviated/Decreased & 10 days & Cure \\
\hline \multicolumn{8}{|c|}{ Disease unrelated to infection } \\
\hline 32 & Right hip joint pain & $60 / \mathrm{F}$ & $\begin{array}{c}3 \mathrm{~min} / 1 \text { - } 2 \text { times/day for } 3 \text { days, then } \\
3 \mathrm{~min} / 2 \text { times/week }\end{array}$ & pain & Alleviated & 4 weeks & PR \\
\hline 33 & Right knee joint pain & $61 / \mathrm{M}$ & $5 \mathrm{~min} / 1$ - 2 times/day for 4 days & pain & Alleviated & 4 days & Cure \\
\hline 34 & Right lumbar pain & $57 / \mathrm{F}$ & $\begin{array}{c}2 \mathrm{~min} / 1 \text { - } 2 \text { times/day for } 4 \text { days, then } \\
2 \mathrm{~min} / 2 \text { times/week }\end{array}$ & pain & Alleviated & 3 weeks & CR \\
\hline 35 & Bilateral gluteal pain & $84 / \mathrm{M}$ & $5 \mathrm{~min} / 1$ time/day & pain & Alleviated & 4 days & Cure \\
\hline 36 & $\begin{array}{l}\text { Acute whipping injury with } \\
\text { swelling and pain }\end{array}$ & $7 / \mathrm{F}$ & $5 \mathrm{~min} / 2$ times/day & pain/size & Alleviated/decreased & 1 day & Cure \\
\hline 37 & Bilateral lower back pain & $23 / \mathrm{F}$ & 30 seconds/ 1 time & pain & Alleviated & 1 day & Cure \\
\hline 38 & Left subscapular pain & $53 / \mathrm{M}$ & $1 \mathrm{~min} / 1$ time & pain & Alleviated & 1 day & Cure \\
\hline
\end{tabular}

S/S: Symptoms or Signs; min: minute(s); ND: no data (unevaluated); PR: partial remission; CR: complete remission. ${ }^{\mathrm{a}}$ Evaluated in 5 minutes after initial session of treating disease; ${ }^{b}$ Changing from therapist to self-administerd to increase frequency and duration of HR.

influenza A and B [12,13]. Patient 10 had a 4-year history of two persistent warts on the left cheek, that had failed to respond to an initial treatment with local fluorouracil and patient 11 has a 14-year history of warts in the left infra-ocular area that shown a poor response to local imiquimod treatments [14].

\subsubsection{Group 2. Patients with Symptoms or Signs Not Related to Infection}

Table 3 provides an overview of the conditions treated in Group 2. Patients 12 to 21 had joint pain. Radiography showed degenerative joint disease in patients 13 and 20. Patient 12 had adhesive capsulitis of the left shoulder (frozen shoulder). Patients 13 and 14 presented with a posture mimicking kyphosis during exacerbations of lumbosacral pain. Patient 22 had a laceration wound about $3 \mathrm{~cm}$ in length and $1 \mathrm{~cm}$ in depth on the right upper eyelid, which caused severe periorbital edematous swellling for 2 days after suturing. Patient 23 had chronic myelogenous leukemia that underwent remission for 1 year on treatment with Glivec and was found to have a painless brownish macular lesion, $3.5 \times 4.2 \mathrm{~cm}$ in size and about $0.3 \mathrm{~cm}$ in thickness, on her left gluteal area. Patient 24 presented with a 3-year history of a severe supine cough (a cough that occurs while lying supine), but was found to have no pulmonary lesion on chest ra- diography [15]. Patient 25 presented with a 2-year history of untreated constipation with progressively decreasing caliber of stool. Patient 26 had a 3-year history of Parkinsonism that was being treated with L-dopa; a brain computed tomography scan of this patient showed no space-occupying lesions. This patient had slurred speech, difficulty in swallowing, rigidity, bradykinesia, right hand tremor, and gait instability that had worsened gradually over a year. Patient 27 had had heavy uterine bleeding ( 7 to 8 fully-soaked pads/day) with suspected uterine malignancy for 2 months.

\subsubsection{Group 3. Patients Treated by the Therapist}

Table 4 provides an overview of the conditions treated in Group 3 with only Patient 28 to 31 having a condition related to infection. Patient 28 had intractable abdominal pain and had been treated with antibiotics and analgesia for 14 months after biliary infection. Patient 29 had recurrent pyuria that had not been cured with antibiotic treatment for 5 years. Patient 30 had a right tender tuboovarian abscess about $3 \times 2 \mathrm{~cm}$ in size that enlarged to $4 \times 2.5 \mathrm{~cm}$ despite antibiotic treatment for 1 week. Patient 31 had a left tender periocular swelling which was indicated to be caused by infection for progressive enlargement to $5 \times 6 \mathrm{~cm}$ in 3 days after a crash to the eye. 
Patient 32 had right hip joint pain for 1 year. The pain got more severe despite regular physical therapy. Pelvic radiography showed osteophytes in acetabuli with likely occult fracture. Patient 33 had right knee joint pain for 2 weeks. Patient 34 had right lumbago caused by a collision 1 month ago and radiography showed probable occult rib fracture. The lumbago did not considerably improve with physical therapy. Patient 35 had bilateral gluteal pain that had been treated with analgesics for 6 months. Patient 36 had an acute left gluteal whipping injury which involved two striped bruised cutaneous swellings about $1 \times 2 \mathrm{~cm}$ and $2 \times 4 \mathrm{~cm}$. Patient 37 had bilateral lower back pain which occurred with dysmenorrhea. Patient 38 had a straining of the left subscapular area.

\subsection{Ou MC Handing Remedy Technique (HR Technique; Figure 1, Table 5)}

The first front-end study (Table 1) showed that the contralateral hand alleviated abdominal pain for all 42 patients. The second front-end study (Table 1) showed the contralateral hand of the examiner alleviated the abdominal pain for $92.3 \%$ patients (36/39, Table 1 ) while the ipsilateral hand did not alleviate pain in any patient (0/39, Table 1$)$. In this study, patient 1 showed alleviation of oropharyngeal pain with the contralateral hand but not with the ipsilateral hand. Patient 23 demonstrated relief from the supine cough when using the contralateral hand, but there was exacerbation with the ipsilateral hand.
Similar results were obtained for patient 18 where right knee joint tenderness was relieved after treatment with the contralateral hand but exacerbated with the ipsilateral hand, as assessed while walking the next day. Each assessment was repeated more than three times, with the same results [5]. Based on the above preliminary findings, only the contralateral hand was used for the HR in this study.

The performance of HR is shown in Figure 1. Briefly, the patient or the therapist places the contralateral hand directly on the affected area (Figure 1, A-1, 2, 3) [1,5]. No hand motion is required. For lesions on or adjoining the midline of the body, the HR is applied first to one side of the lesion and then the other (Figure 1, B-1, 2, 3 ). The pressure applied depends on the depth of the lesion with greater pressure being applied to deeper lesions (Figure 1, C-1, 2, 3). One or more fingers or the back of hand can be used if the palm cannot reach the affected area (Figure 1, A-3, B-3, and C-3). For skin lesions, the palm may be kept about $0.5 \mathrm{~cm}$ over the lesion without touching the skin (Figure 1, A-2) $[8,16]$.

\subsection{Outcome Evaluations}

With the exception of fever, symptoms and signs were evaluated immediately before and 5 minutes after application of HR. The severity of pain was evaluated with a visual analog scale (VAS) by the patients [17]. Promi-

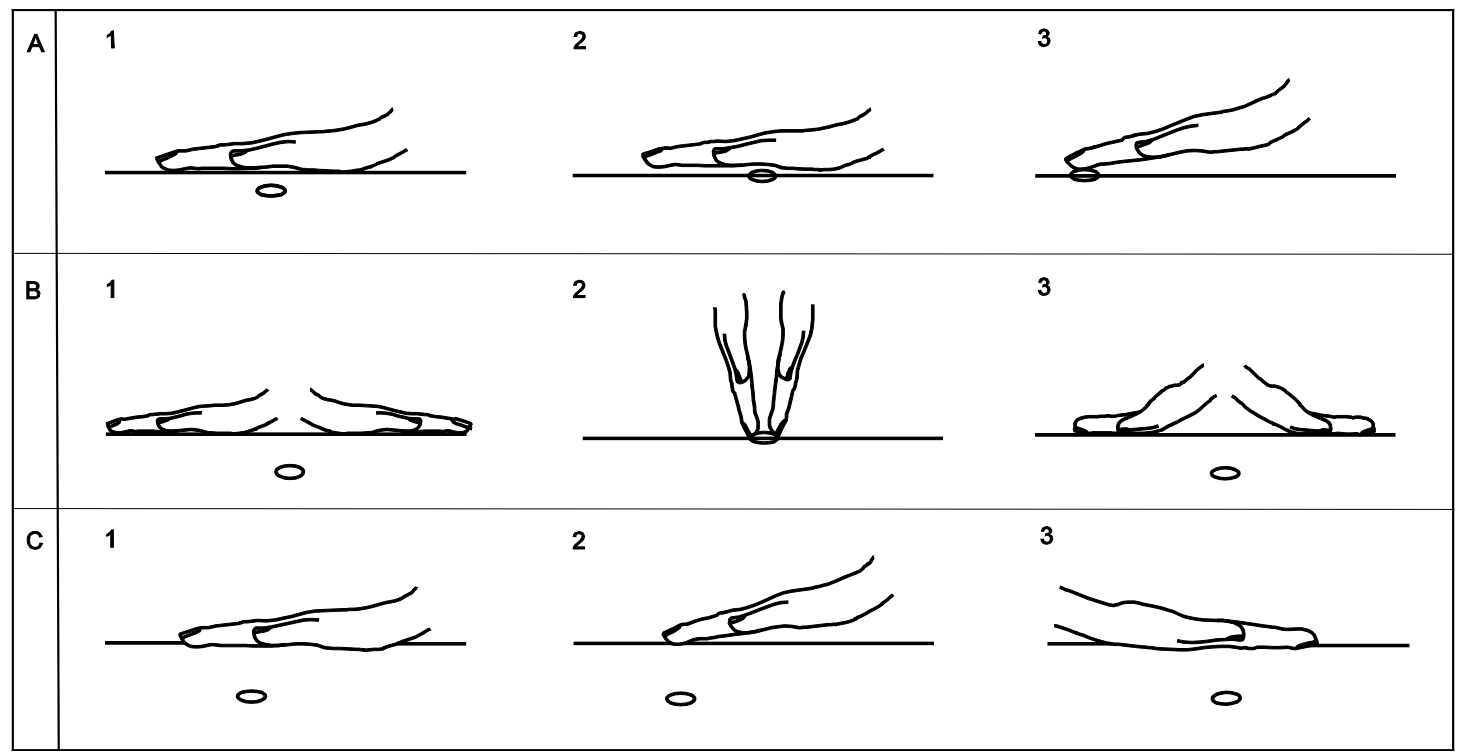

Figure 1. Schematic of the Ou MC handing remedy (HR) technique. The HR was performed by placing the contralateral hand on the affected area (A-1, 2, 3). For lesions on or adjoining the midline of the body, the HR is applied first to one side of the lesion and then the other (Figure 1, B-1, 2, 3). The pressure applied depends on the depth of the lesion with greater pressure being applied to deeper lesions (Figure 1, C-1, 2, 3). One or more fingers or the back of hand can be used if the palm cannot reach the affected area (Figure 1, A-3, B-3, C-3). For skin lesions, the palm may be kept about $0.5 \mathrm{~cm}$ over the lesion without touching the skin (Figure $1, \mathrm{~A}-2$ ). $\bigcirc=$ lesion. 
Table 5. Practical points for the application of Ou MC handing remedy (HR).

11 The HR is performed by placing the contralateral hand directly on the affected area according to Ou MC decrescendo phenomenon
2 For lesions on or adjoining the midline of the body, the HR is applied first to one side of the lesion and then the other.
The effects of Ou MC decrescendo phenomenon are related to the duration, frequency of administration and may be affected by the
distance between the hand and the lesion.
If HR is not efficacious, measures such as getting the hand nearer to the lesion, applying other hand gesture and increasing the dura-
tion or frequency of administration may be helpful ${ }^{\mathrm{a}}$.

${ }^{\mathrm{a}}$ The effect or appropriate duration and frequency of HR treatment for various diseases requires further study; ${ }^{\mathrm{b}}$ Whether emotional disturbance affects the efficacy of the Ou MC decrescendo phenomenon is not explored in the present study.

nent mitigation of symptoms or signs was defined as a $>50 \%$ decrease. In patients with fever, body temperature was measured via an ear thermometer MT-30 (accuracy: $\pm 0.1^{\circ} \mathrm{C}$ in $37.0^{\circ} \mathrm{C}$ to $39.1^{\circ} \mathrm{C}$; Terumo, Tokyo, Japan) at 30 minutes and 90 minutes after HR. The evaluation of granulomas or cutaneous lesions was based on observing changes in lesion size. The amount of rhinorrhea and swelling associated with infection or injury was evaluated by a single physician before and after treatment. The severity of the supine cough was reported by both the patient and clinic staff during evaluation at the clinic. Constipation and small stool caliber were selfreported by the patient. Improvements in the symptoms of Parkinsonism were evaluated using the mental, behavior, mood (Part 1), daily living activity (Part 2) and motor examination (Part 3) of the Unified Parkinson's Disease Rating Scale immediately before and 2 months after HR. The uterine bleeding was evaluated on the gynecological examining table via a vaginal speculum before and after initial HR and then reported by the patient.

\subsection{Emotional Evaluation}

Emotional factors may influence the effectiveness of treatment. Therefore, the generalized anxiety disorder-7 item scale (GAD-7) was used to document clinical anxiety during administration of the HR in order to evaluate the potential impact of anxiety on the treatment outcome [10].

\subsection{Statistical Methods}

The sign test was used to assess the clinical efficacy when the patients were evaluated to assess the immediate and cumulative effects of OuDP. Fisher's exact test was used to compare the immediate effect of OuDP by selfadministered HR and that by abdominal palpation or therapist-administered HR. A $p$-value of $<0.05$ was considered statistically significant.

\section{Results}

\subsection{Emotional Evaluation}

All patients showed GAD-7 scores $<5$ in the duration of treatment, indicating the absence of GAD and suggesting that anxiety is not likely to have influenced the treatment results. The sections below provide detailed results by condition.

\subsection{Group 1. Symptoms and Signs Related to Infection Treated with Self-Administered HR}

\subsubsection{Recurrent Oropharyngeal Infections}

The oropharyngeal infections in patient 1 recurrently occurred with suppurative swelling lesions on the right side of the tongue after biting, the left sublingual salivary gland, the left side of the lips and gingival area, and tender mild swelling on the left and right side of the pharynx. The pain caused by the infection showed prominent relief 5 minutes after receiving 30 seconds to 5 minutes of HR (Figure 1, A-3 or C-1 or 2); the duration of each HR session depended on the intensity of pain. The patient continued to perform HR for 30 seconds to 5 minutes 2 to 3 times daily, and all lesions subsided within 1 week.

\subsubsection{Pain and Swelling of the Right Sublingual and Gingival Area}

Patient 2 initially administered HR to the outside of the right submandibular triangle area (1-minute sessions preformed twice daily; Figure 1, A-1 or C-1). However, the pain caused by the submucosal swelling in the right sublingual and gingival areas was not relieved to a significant degree after 5 days of therapy. Therefore, the patient was instructed to modify the procedure by placing his left index finger directly on the lesion inside the mouth (Figure 1, A-3). The pain was prominently relieved after the initial intra-oral treatment, and subsequent sessions also showed a similar improvement. The 
tender swelling was completely resolved 4 days after switching to the new procedure.

\subsubsection{Infectious Granuloma}

The granuloma in patient 3 was on the left index finger and measured about $0.8 \mathrm{~cm}$ (width) $\times 0.9 \mathrm{~cm}$ (height) $\times 0.4 \mathrm{~cm}$ (thickness) at presentation. The patient performed 5-minute sessions of HR (Figure 1, A-3) twice daily. The granuloma had decreased to $<0.1 \mathrm{~cm}$ in thickness on day 4 and was fully resolved 1 week later. The granuloma on the sternum in patient 4 measured about $0.6 \mathrm{~cm}$ (width) $\times 0.7 \mathrm{~cm}$ (height) $\times 0.3 \mathrm{~cm}$ (thickness) . The patient performed HR for 2 minutes twice daily (1 minute on each side of the granuloma, Figure 1, B-2). The granuloma diminished to about $0.1 \mathrm{~cm}$ in thickness 1 hour after the initial HR session and had fully resolved 4 days later.

\subsubsection{Subcutaneous Edematous \\ Swelling of the Right Leg Due to Cellulitis}

Patient 5 presented with subcutaneous edematous swelling of the right leg due to cellulitis, which had not completely subsided after 2 weeks of intravenous antibiotics and intermittent FIR treatment. At this point antibiotics were continued, but FIR was discontinued and HR was initiated (Figure 1, A-1). The swelling decreased significantly 5 minutes after the initial 30-minute HR session on day 1 , and showed further resolution on day 2 (two 20-minute treatments) and day 3 (three 20-minute sessions). The swelling had remitted completely 1 week after initiating the therapy, and the cellulitis did not relapse during a follow-up period of 6 months.

\subsubsection{Rhinorrhea}

Patients 6 and 7 with rhinorrhea performed HR for 5 minutes (patient 6) or 1 minute (patient 7) twice daily on each side of the paranasal area for two days (Figure 1, $\mathrm{C}-1)$. The amount of discharge decreased prominently after the initial HR and subsequent sessions. However, both patients discontinued the HR after repeated recurrence and were eventually cured by antibiotic treatment.

\subsubsection{Fever with Headache}

The headache affecting patients 8 and 9 showed rapid improvement with 10 minutes of HR applied to the bilateral temporal areas (5 minutes on each side; Figure 1, A-1). Body temperature was measured for only one patient (patient 8, Table 2), and showed regression from $38.3^{\circ} \mathrm{C}$ before $\mathrm{HR}$ to $38.1^{\circ} \mathrm{C}$ at 30 minutes and $37.7^{\circ} \mathrm{C}$ at 90 minutes after the initial HR session. The fever did not fully resolve until 3 (case 8) or 4 (case 9) days after HR was initiated (Table 2). However, both patients reported that 2 to 3 minutes of HR soothed recurrent episodes of associated headaches during this period.

\subsubsection{Facial Warts}

Before HR, the warts on the left cheek of patient 10 measured $5.3 \times 3.8 \mathrm{~mm}$ and $4.6 \times 3.9 \mathrm{~mm}$. A small biopsy of each lesion showed Verruca vulgaris. The patient performed HR irregularly during the first 3 months of treatment, and the size of the warts did not decrease noticeably during this period. Thereafter, the patient performed HR (Figure 1, A-2) for about 20 to 30 seconds once or twice a day on most days. Both warts began to decrease in size as assessed by biweekly evaluation and had completely resolved 2 months later. The infra-ocular wart of patient 11 measured $1.9 \times 2.0 \mathrm{~mm}$ and no biopsy was performed. The patient performed HR (Figure 1, A-3) for 20 to 30 seconds three times a day. The size of wart reduced to $1.0 \times 1.1 \mathrm{~mm}$ at the end of first week and was cured 1 month later.

\subsection{Group 2. Symptoms and Signs Not Related to Infection Treated with Self-Administered HR}

\subsubsection{Joint Tenderness}

All patients with joint pain (patients 12 to 21) showed prominent pain relief immediately after each session of HR. The stretch limitation due to frozen shoulder in patient 12 did not resolve completely, but was significantly improved with repeated treatment (Figure 1, A-1, C-1) over a period of two week. The two patients with kyphosis-mimicking posture (patients 13 and 14) performed HR with the dorsal side of the contralateral hand to the lumbosacral area of the back (Figure 1, B-3). HR relieved the lumbosacral pain, which ameliorated the kyphosis-mimicking gesture. The joint pain of patients 12 to 17 relapsed occasionally and was treated successfully with HR. Patient 18 to 21 withdrew from the study after complete remission was achieved in the first week.

\subsubsection{Swelling of Periorbital Area of the Right Eye}

Patient 22 administered 5-minute sessions of $\mathrm{HR}$ (Figure 1, C-1) to the right eye once daily for 3 days. The swelling decreased to a great extent after each session and had subsided completely 2 days after the final session of HR.

\subsubsection{Perineal Macula Skin Lesion with Chronic Myelogenous Leukemia}

After failed antibiotic treatment, patient 23 performed HR for 2 minutes on the perineal lesion (Figure 1, A-3) twice daily. The perineal lesion was found to be cured 2 week later. 


\subsubsection{Supine Cough}

The supine cough of patient 24 was prominently suppressed by the first 5-minute HR session, which was performed by putting the contralateral hand on the area of discomfort (Figure 1, A-1, C-2) while in the supine position before sleeping or during during-office evaluation. After 3 months with HR performed every night before sleep, the supine cough was not fully cured but had become much milder.

\subsubsection{Defecation Difficulty with Progressively Decreasing Caliber of Stool}

Patient 25 performed HR by putting the right hand over the left colon and sigmoidal region of the abdomen (Figure 1, C-1) and a finger (index or middle) of right hand on left perineal area (Figure 1, C-2) for 30 seconds separately before sleeping, and during defecation. After 1 week of HR, defecation became easier and there was increased stool caliber, which had enlarged to the normal size over 3 weeks of treatment. HR was also effective when recurrences occurred.

\subsubsection{Parkinsonism}

Patient 26 with Parkinsonism applied HR to the bilateral temporal areas, one side at a time (Figure $1 \mathrm{C}-1,3$ ) when sleeping and having naps. Improvements in rigidity, bradykinesia, hand tremor, and gait instability were noted after 1 month of HR. The Unified Parkinson's Disease Rating Scale score before and after 2 months of HR, respectively, were “ 1 vs. 1 ” for Part 1 , "28 vs. 19" for Part 2 and "26 vs. 19" for Part 3, which indicated improvement with respect to the Parkinsonism of this patient.

\subsubsection{Leiomyosarcoma}

Patient 27 applied HR (Figure 1, C-1) alternatively over abdomen on each side of uterus in a supine position for about 2 - 3 minutes three to four times daily. During the initial HR without any medication, the heavy uterine bleeding of this patient immediately decreased dramatically as observed by vaginal speculum. The subsequent HR was also found to be effective at minimizing heavy uterine bleeding until a hysterectomy with lymphadenectomy was performed 3 weeks later. The pathology of the uterus showed the presence of leiomyosarcoma with a diameter of $10 \mathrm{~cm}$ localized to the body of the uterus. No pelvic or para-aortic lymphatic metastasis was identified.

\subsection{Group 3 Symptoms and Signs Treated with HR by the Therapist}

\subsubsection{Intractable Abdominal Pain after Recurrent Biliary Tract Infection}

Patient 28 received HR (Figure 1, B-1) for 1 minute, two to three times a day. The abdominal pain subsided 1 week later but recurred later when no HR was performed.

\subsubsection{Intractable Pyuria}

Patient 29 received HR (Figure 1, C-1) for 2 minutes alternatively over each renal and bladder area once weekly for 3 weeks. The dysuria was reported to be relieved during the next day and weekly urinary analysis showed that the number of leukocytes in urine had decreased to less than five for each high power microscopic field.

\subsubsection{Right Intractable Tuboovarian Abscess}

Patient 30 received HR (Figure 1, C-1, 2) by pressing the hand deeply near the abscess. HR was performed for 2 minutes, twice a day and tenderness was alleviated but the effectiveness decreased after 2 days of treatment. The HR was then performed for 5 minutes, three to four times a day. The tenderness was alleviated significantly and sonography showed that the abscess dissipated 1 week later. The vaginal culture showed Burkholderia cepacia which was resistant to antibiotics in use.

\subsubsection{Left Periocular Swelling with Tenderness}

Patient 31 received HR (Figure 1, C-1) for 1 minute, once or twice a day. The tenderness and swelling was alleviated significantly but was still present after 3 days of treatment. The patient then performed the HR herself 5 minutes, 3 times a day. As a result, the periocular swelling was cured after 1 week.

\subsubsection{Left Hip Joint Pain}

While discontinuing physical therapy and analgesics, patient 32 received HR (Figure 1, C-1, 2) 1 to 2 times a day by pushing the hand to the hip joint for 3 minutes for 3 days, then 2 times a week. The patient experienced pain alleviation following all HR sessions. The joint pain significantly subsided 4 weeks later. The results were more beneficial in comparison to the physical therapy received.

\subsubsection{Right Knee Joint Pain}

Patient 33 received HR (Figure 1, C-1) for 5 minutes, 1 to 2 times a day. The knee joint pain was significantly alleviated with the initial HR. Following HR sessions showed progressive pain alleviation. The knee joint pain was cured 1 week later.

\subsubsection{Right Lumbago}

Patient 34 discontinued physical therapy with analgesics and received HR (Figure 1, C-1, 3) for 2 minutes, 
1 to 2 times a day for 4 days, then 2 times a week. The right lumbago was significantly alleviated with the initial HR. Following HR sessions also showed pain alleviation. The pain completely subsided 3 weeks later. The results were more beneficial in comparison to the physical therapy received.

\subsubsection{Bilateral Gluteal Pain}

Patient 35 received HR (Figure 1, C-1) alternatively in the bilateral glueal area for 10 minutes, once a day for 4 days. The gluteal pain was alleviated after the initial HR and was cured 4 days later.

\subsubsection{Acute Whipping Injury}

Patient 36 received HR (Figure 1, A-3) for 5 minutes to each lesion and the pain and swelling was significantly alleviated. Another HR was applied 12 hours later and the two cutaneous bruised swellings had dissipated by the next day.

\subsubsection{Soft Tissue Pain}

Patients 37 and 38 only had one session of HR (Figure 1, C-2) with which the pain was initially significantly relieved and became absent in the next day.

\subsection{Statistical Analysis}

Overall, the OuDP demonstrated significant immediate effects among both the self-administered group (20/20, $100 \%, 7$ unevaluated), the therapist-administered group $(10 / 10,100 \%, 1$ unevaluated) and the cumulative effects (38/38, 100\%) (All, $p<0.001$, 2-sided). There was no difference between the ability of the patient to bring about an immediate effect $(20 / 20$, Tables 2,3$)$ and when the examiner or therapist carried out the treatment (88/91, Tables 1 and 4, $p>0.5$, 1-sided).

\section{DISCUSSION}

Manual therapy is a clinical approach that utilizes specific hands-on techniques to modulate pain, increase range of motion, and reduce or eliminate soft tissue inflammation. Specific forms of manual therapy may be directed to the joints (mobilization and manipulation), soft tissue (massage), or nerves (neural dynamic interventions). Studies show that manual therapy seems to be able to provide immediate and/or short-term clinical effects, but there is little support for there being long term functional outcomes [3]. Therapeutic touch, another handson therapy, involves energy being directed by the practitioner's hands to improve the body's ability to heal, to inspire balance, and to invoke a mind-body connection. However, studies show that therapeutic touch techniques do not seem to produce conclusive clinical effects and the underlying mechanism also remains speculative and unproven [4]. Conclusively, all rigorously controlled studies to date involving such complementary medicine, including hands-on therapy, have been shown not to work better than placebo controls, as can be seen in the declaration by the National Center for Complementary and Alternative Medicine, USA [18]. However, the OuDP, which can be invoked with HR, not only brings about immediate effects, but also seems to bring about longterm functional improvements such as remission or curing of diseases. The OuDP may provide solid evidence to account for the effectiveness of various hands-on therapeutic techniques.

OuDP appears to be consistently effective based on the distance between the hand and the lesion, on the duration of the treatment and on the frequency of performance. The mechanism of action of OuDP remains unclear, but the potential roles of several sensory factors merit exploration. When HR is performed, the treated area not only perceives the performing hand by proprioception or touch, but through by temperature change as well. Elevation of tissue temperature by thermal therapy has been shown to increase cell-mediated cytotoxicity, which may have anti-bacterial, anti-parasitic, anti-viral, and antineoplastic effects when treating dermatological diseases [19]. However, two findings argue against the involvement of thermal effects in this study. Firstly, the patient with cellulitis in this series responded to HR despite not benefitting from FIR. Secondly, when the ambient temperature during treatment is room temperature or below, the hand is usually cooler than the body. The HR described here does not require any hand movement or skin contact when treating superficial lesions [8]. Thus, touch may also not be essential to the effectiveness of the HR.

The recovery of tissue from diseases not related to infection indicates that a restoration of normal tissue function seems to be occurring after administration of HR. Restoration of normal tissue function may involve reestablishing host defense systems, which contribute to defense against microorganisms, inflammation, degenerative changes, and tumors $[20,21]$. However, the restoration of normal tissue function provided by the initial treatment may be inadequate to cure the disease, as was evidenced by the finding that many patients required repeated sessions of HR to yield a long-term effect. The two patients with rhinorrhea in this study responded to antibiotic therapy after HR failed to give persistent relief, which suggests that restored tissue function alone is not always sufficient to cure an infection. Laboratory evaluations of tissue function could be useful and allow documentation of the restorative action of OuDP, but are beyond the scope of the present work.

Studies have shown that inflammation on one side of a topographically symmetrical living organisms may cause further inflammation on the contralateral side [2]. How- 
Table 6. Summary of the relief of pain and other symptoms and signs with the effect by Ou MC decrescendo phenomenon for 119 patients from 2006-2013.

\begin{tabular}{cccccc}
\hline $\begin{array}{c}\text { Symptoms or } \\
\text { signs }\end{array}$ & $\begin{array}{c}\text { Number of } \\
\text { patients }\end{array}$ & $\begin{array}{c}\text { Immediate improvement by } \\
\text { examiner }\end{array}$ & $\begin{array}{c}\text { Immediate effect by } \\
\text { self-administered HR }\end{array}$ & $\begin{array}{c}\text { Immediate effect by } \\
\text { therapist-administered HR }\end{array}$ & Cumulative effect by HR \\
\hline Pain & $106^{\mathrm{a}}$ & $78 / 81(97.1 \%)$ & $14 / 14(100 \%)$ & $11 / 11(100 \%)$ & $25 / 25(100 \%)$ \\
Others & $13^{\mathrm{b}}$ & $\mathrm{ND}$ & $6 / 6$ & ND & $13 / 13(100 \%)$ \\
\hline
\end{tabular}

HR: Ou MC handing remedy; ND: no data (unevaluated). ${ }^{a}$ All caused by an inflammation with infection or non-infection condition; ${ }^{\text {Inflammatory reaction }}$ (6/13), oncological disease (4/13), and organ dysfunction (3/13).

ever, the OuDP invokes a restorative effect to the opposed side of the body rather than a spread of the harmful effects of inflammation which is probably mediated through a neurological transmission. A similar phenomenon to OuDP was described in the studies of the snapping shrimp where it was found that the contralateral snapper claw of the snapping shrimp affects the development of the new claw after the claw is lost in order to achieve a bilateral symmetry in both shape and fiber composition of bilateral claw [22]. Interestingly, the exposure to conspecific mutual interactions of other snapping shrimps also triggers such claw transformation [22]. Similarly, the OuDP can be invoked via HR using both self and therapist administration. What signals are imparted during such exposure to such interaction remains to be elucidated.

\section{LIMITATIONS}

Although HR showed tissue functional restoration for diseases other than inflammation (Table 6), the number of patients remains limited. Patients with excessive anxiety were not involved based on a GAD standard. The influence of emotion still needs to be evaluated because it has been shown that emotions may affect outcome of hands-on treatment [9]. HR by the examiner failed to invoke OuDP in three cases (3/81, Table 1$)$, which suggests that differences exist between self-administered HR and therapist administered HR.

\section{CONCLUSION}

In summary, in this study the OuDP yielded not only immediate but also consistent long-term effects on patients who were suffering from a variety of infectious and non-infectious conditions. The OuDP seemed to accelerate the recovery processes for inflammation, degenerated diseases, tissue dysfunction and oncological changes. The OuDP treats diseases in a different way from conventional medicine and may thus provide a new avenue for better understanding of human physiology and disease [23]. The effect of OuDP may also provide evidence supporting the clinical application of other hands-on therapies. These preliminary findings warrant further investigation.

\section{ACKNOWLEDGEMENTS}

We thank the help from Dr. Su, Chin Hsu, Ms. Ou, Yi Jen.

\section{REFERENCES}

[1] Ou, M.C., Pang, C.C., Ou, D. and Su, C.H. (2012) The implications of abdominal palpation with Ou MC manipulation for women with acute abdomen. American Journal of Emergency Medicine, 30, 421-425. http://dx.doi.org/10.1016/j.ajem.2011.01.008

[2] Shenker, N., Haigh, R., Roberts, E., Mapp, P., Harris, N. and Blake, D. (2003) A review of contralateral responses to a unilateral inflammatory lesion. Rheumatology (Oxford), 42, 1279-1286. http://dx.doi.org/10.1093/rheumatology/keg397

[3] Cook, C. (2011) Immediate effects from MT: Much ado about nothing? The Journal of Manual \& Manipulative Therapy, 19, 3-4. http://dx.doi.org/10.1179/106698110X12804993427009

[4] So, P.S., Jiang, Y. and Qin, Y. (2008) Touch therapies for pain relief in adults. Cochrane Database of Systematic Reviews, 4, Article ID: CD006535.

[5] Ou, M.C., Pang, C.C. and Ou, D. (2012) A primitive approach for Ou MC handing remedy with a comparison to the ancient laying on of hands. The 15th Annual Meeting of the British Infection Association, 25 May 2012, London, 9.

[6] Perrie, K.J., Fontanilla, I., Thomas, N.G., Booth, R.J. and Pennebaker, J.W. (2004) Effect of written emotional expression on immune function in patients with human immunodeficiency virus infection: A randomized trial. Psychosomatic Medicine, 66, 272-275. http://dx.doi.org/10.1097/01.psy.0000116782.49850.d3

[7] Carlson, L.E., Speca, M., Patel, K.D. and Goodey, E. (2003) Mindfulness-based stress reduction in relation to quality of life, mood, symptoms of stress, and immune parameters in breast and prostate cancer outpatients. Psychosomatic Medicine, 65, 571-581. http://dx.doi.org/10.1097/01.PSY.0000074003.35911.41

[8] Ou, M.C., Pang, C.C. and Ou, D. (2012) The evidence for mechanism of an antineoplastic effect of a successful emotional treatment on cutaneous neoplasms. The 23rd International Congress on Anti-Cancer Treatment, 31 January-3 February 2012, Paris, 326-327.

[9] Kerr, C.E., Wasserman, R.H. and Moore, C.I. (2007) Cortical dynamics as a therapeutic mechanism for touch healing. Journal of Alternative and Complementary Med- 
icine, 13, 59-66. http://dx.doi.org/10.1089/acm.2006.5245

[10] Spitzer, R.L., Kroenke, K., Williams, J.B. and Löwe, B. (2006) A brief measure for assessing generalized anxiety disorder: The GAD-7. Archives of Internal Medicine, 166, 1092-1097. http://dx.doi.org/10.1001/archinte.166.10.1092

[11] Department of Health, Executive Yuan, ROC (1993) No. 82075656, November 1993. http://www.mohw.gov.tw/cht/DOCMAP/DM1 P.aspx?f l ist no $=782 \&$ fod list no $=4240 \&$ doc no $=32589$

[12] Eccles, R. (2005) Understanding the symptoms of the common cold and influenza. The Lancet Infectious Diseases, 5, 718-725. http://dx.doi.org/10.1016/S1473-3099(05)70270-X

[13] Vasoo, S., Stevens, J. and Singh, K. (2009) Rapid antigen tests for diagnosis of pandemic (Swine) influenza A/H1N1. Clinical Infectious Diseases, 49, 1090-1093. http://dx.doi.org/10.1086/644743

[14] Massing, A.M. and Epstein, W.L. (1963) Natural history of warts: A two-year study. The Archives of Dermatology, 87, 306-310. http://dx.doi.org/10.1001/archderm.1963.0159015002200 4

[15] Bonnet, R., Jörres, R., Downey, R., Hein, H. and Magnussen, H. (1995) Intractable cough associated with the supine position. Effective therapy with nasal CPAP. Chest, 108, 581-585. http://dx.doi.org/10.1378/chest.108.2.581

[16] Ou, M.C., Ou, D., Pang, C.C. and Ou, Y.J. (2013) The implication of a self-administered remedy method-Ou
MC handing remedy for emergency medicine. Annual Scientific Conference of College of Emergency Medicine, 24-26 September 2013, London.

[17] Bijur, P.E., Silver, W. and Gallagher, E.J. (2001) Reliability of the visual analog scale for measurement of acute pain. Academic Emergency Medicine, 8, 1153-1157. http://dx.doi.org/10.1111/j.1553-2712.2001.tb01132.x

[18] Offit, P.A. (2012) Studying complementary and alternative therapies. JAMA, 307, 1803-1804.

[19] Badgwell Doherty, C., Doherty, S.D. and Rosen, T. (2010) Thermotherapy in dermatologic infections. Journal of the American Academy of Dermatology, 62, 909-927. http://dx.doi.org/10.1016/j.jaad.2009.09.055

[20] Ou, M.C., Ou, D., Pang, C.C. and Ou, Y.J. (2013) The mechanism of antineoplastic effect for Ou MC handing remedy. The 24th International Congress on Anti-Cancer Treatment, 4-6 February 2013, Paris, 326.

[21] Yao, X., Li, H. and Leng, S.X. (2011) Inflammation and immune system alterations in frailty. Clinics in Geriatric Medicine, 27, 79-87. http://dx.doi.org/10.1016/j.cger.2010.08.002

[22] Pearce, J. and Govind, C.K. (1987) Spontaneous generation of bilateral symmetry in the paired claws and closer muscles of adult snapping shrimps. Development, 100, 57-63.

[23] Ou, D., Ou, M.C. and Pang, C.C. (2012) Time may affect the visibility of dark matter and its corresponding space Bulletin of the American Physical Society, 57, 71. 